Research Article

\title{
Application of remote sensing techniques for analyzing operation of upstream reservoirs in transboundary river basins of Vietnam
}

\author{
Tran Anh Phuong ${ }^{*}$, Tran Manh Cuong ${ }^{1}$, Nguyen Hoang Van', Pham Nhat Anh', \\ Nguyen Anh Duc ${ }^{1}$, Duong Hong Son ${ }^{1}$ \\ ${ }^{1}$ Water Resources Institute: phuongtran.monre@gmail.com; manhcuongkt11@gmail.com; \\ vannh5nk@wru.vn; phamnhatanh2803@gmail.com; nganhduc@yahoo.com; \\ dhson.monre@gmail.com. \\ * Correspondence: phuongtran.monre@gmail.com; Tel.: +84961776683
}

Received: 12 June 2020; Accepted: 18 August 2020; Published: 25 August 2020

\begin{abstract}
Operation of upstream reservoirs in transboundary river basins strongly influences water resources in Vietnam. However, due to the lack of observation data, it is difficult to have sufficient information on their operation. In that context, remote sensing with a global coverage has a great potential to provide this information. This study estimated the time series of surface water area by processing Landsat images from the Google Earth Engine platform. Then, the area - volume - elevation relationship constructed from DEM was used to derived the water level and volume from the surface water area datasets. The results showed that remote sensing enables to monitor temporal variations of water level and volume of reservoirs. Remote sensing can also detect the wet and dry periods and determine the operation of reservoirs, which supports to improve inflow prediction to Vietnam, and therefore, improve the water resources management in the transboundary rivers.
\end{abstract}

Keywords: Transboundary river; Remote sensing; Reservoir operation; Water level.

\section{Introduction}

Water plays a crucial role for the sustainable development. In the context of population growth and climate change, water demand for domestic and socio-economic development will continue to increase in the foreseeable future while water resources tend to be exhausted [1]. This leads to aggressively serious disputes and conflicts over water resources amongst countries, especially in transboundary river basins [2]. Hence, ensuring water security for countries located at the downstream of transboundary rivers is a necessity.

Water resources in Vietnam are heavily influenced by the international waters. Approximately $61 \%$ of the total water in the territory of Vietnam comes from foreign countries. Six out of nine major rivers in Vietnam share the basins with other countries. In particular, the two largest rivers, the Mekong and Red River, have larger basin areas outside Vietnam's territory. The basin area of Mekong River in Vietnam's territory accounts for only $8.7 \%$ of the entire basin area. The annual flow in Vietnam's territory only contributes about $10 \%$ of the annual flow of the Mekong river basin. For the Red river, $50.7 \%$ of the basin area is located in China and Laos, while only $49.3 \%$ is in Vietnam. The total rainfall in the Red river basin in Vietnam only accounts for $57.8 \%$ of the total rainfall in the whole basin. The variation of water resources in Vietnam is, thus, strongly depends on changes in water resources originated from outside the country's boundary, influencing water security in Vietnam. 
One of the most threats for water security of Vietnam is the construction of hydropower dams at the upstream of the Mekong and Red rivers. Located at the downstream, Vietnam has been largely influenced by the operation of these reservoirs. In order to reduce negative effects of these dams, water resources prediction and management in the Mekong and Red river basins are very important. However, the effectiveness of water resources prediction and management strongly depends on information about reservoir condition and operation. As a result, assessing conditions of water level and volume of reservoirs and determining their operation schedule in transboundary rivers are essential for better management and prediction of water resources.

Recently, remote sensing with its high spatial coverage has been widely used in hydrology and water resources [3]. Remote sensing not only helps in generating topography and land cover maps, and serving for hydrological parameter estimation but also provides important inputs such as data on precipitation, temperature, evaporation and soil moisture for flood and drought prediction. Particularly, application of remote sensing for water resources monitoring in transboundary rivers has attracted the attention of researchers over the world. For example, in Bangladesh, Biancamaria et al. [4] used Topex/Poseidon satellite altitude to measure water levels in India to increase forecasting time in the transboundary rivers located both in Bangladesh and India. Nishat and Rahman [5] used remote sensed images of topography, land cover and water level to calibrate and validate hydrodynamic model in Hang-Brahmaputra-Meghna (GBM) international river basin. Zhang et al. [6] used water surface areas estimated from MODIS satellite images and the elevation-water surface area relationship to monitor the storage variation of reservoirs in South Asia. In Vietnam, the project on "Supporting the cooperation program between the two governments of Vietnam and the Netherlands" on Water and Climate Services for Transboundary Water and Disaster Risk Management focuses on using geographic and remote sensing information systems to improve monitoring and modelling of transboundary water sources in the Da River basin. The National Remote Sensing Department (Ministry of Environment and Natural Resources) has implemented the project named "Monitoring water resources variation, water exploitation and water consumption in foreign territories of the Red and Mekong river basins", which assessed the exploitation and consumption of water resources in the upstream foreign parts of the Red and Mekong river basins as well as their impacts on flow regime in these rivers in Vietnam. However, so far there have been only few studies that use remote sensing for monitoring reservoirs in transboundary river basins. However, so far using remote sensing techniques to investigate the reservoir operation in the transboundary river basins has not been intensively studied.

The objective of this study is to explore the capability of remote sensing to investigate the temporal variations of reservoirs and analyze their operation schedule in the Mekong and Red rivers. To do that, we process the Landsat- 8 data on the Google Earth Engine (GEE) platform to estimate the water surface area. After that, based on the area-elevation-volume relationship developed from the DEM topography map, we quantify the reservoir water level and volume. Finally, the temporal variations of water level and volume are analyzed to determine the reservoir operations. The reliability of this approach was proved by our previous study which compared the water level obtained by the Landsat images with the observed data at the Ka Nak reservoir in Kon-Ha Thanh River basin [7].

\section{Methodology and data}

\subsection{Methodology}

Figure 1 presents the approach that we used to analyze the spatiotemporal variations of reservoir water levels and volumes as well as explore their operation rules. As can be seen in 
the figure, the input data for this approach is the Landsat images and topography of reservoirs. While the Landsat images were used to estimate the surface water areas of reservoirs, the topography data were used to construct the surface water area-water levelwater volume relationship. The water level and water volume of each reservoir were obtained from the Landsat-derived water surface areas using the surface water area-water level-water volume relationship. Finally, we analyzed the spatiotemporal variations of the water surface area, water level and water volume of reservoirs and study the operation rules of these reservoirs. In order to perform this approach, we used two main tool including GEE platform and ArcGIS software, which are presented as below.

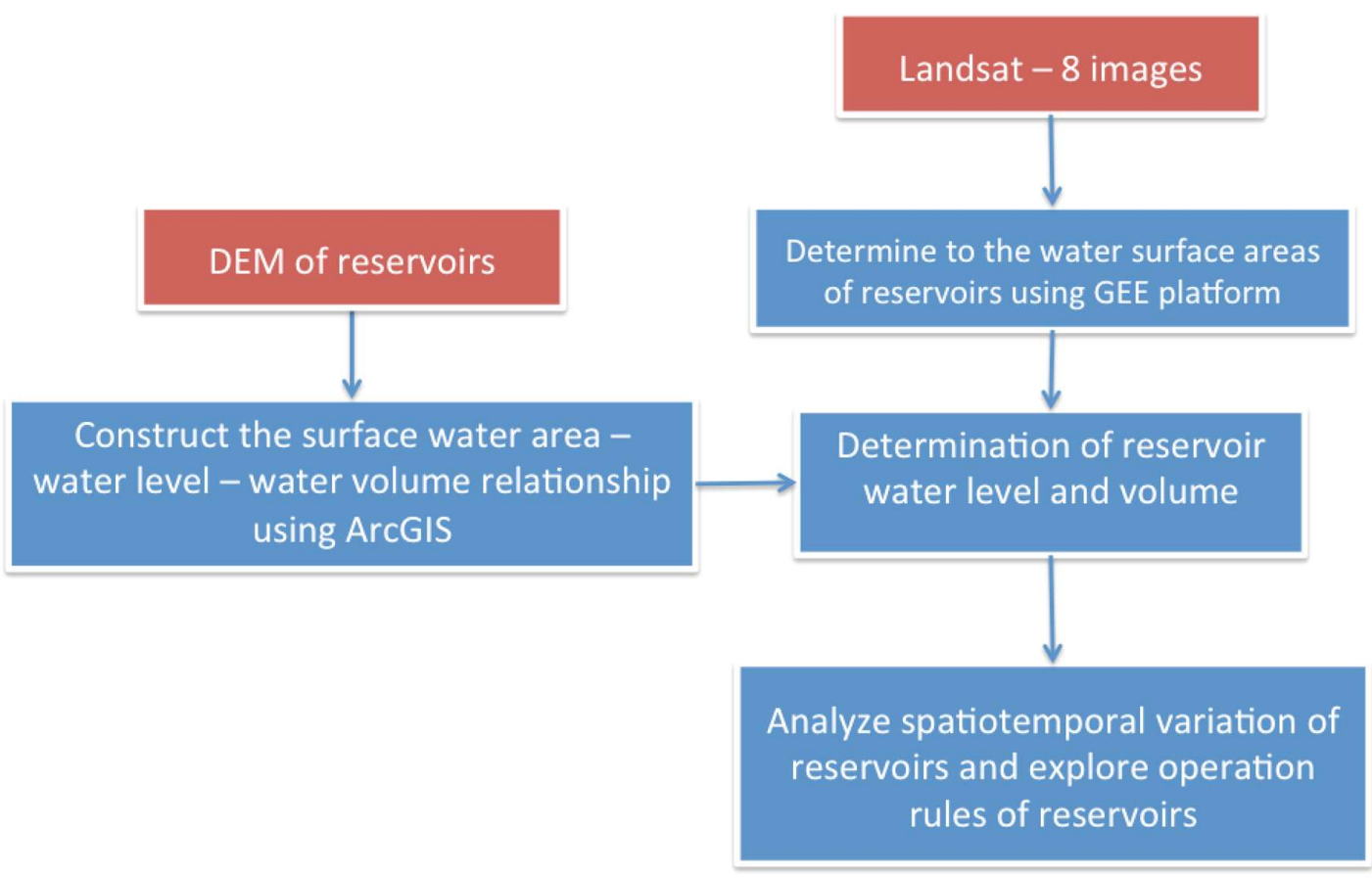

Figure 1. Flowchart that using remote sensing technique to investigate the spatiotemporal variation of reservoirs and their operation rules in the Mekong and Red river.

Google Earth Engine platform: This platform is developed by Google Inc. GEE combines satellite images and geospatial datasets with analyzing capabilities to allow users to detect changes, map trends, and quantify differences on the Earth's surface over a period of time (Figure 2). Cloud-based GEE platform can process a large data volumes with much shorter time and higher accuracy comparing to the conventional approach. Instead of downloading and processing each satellite image as in the conventional approach, GEE platform allows users to simultaneously process multiple images on Google's servers, which significantly saves computer resources and computation time. Another advantage of using this platform is that it permits to delineate the study area and perform spatio-temporal analysis on this area using build-in functions or user-developed scripts in JavaScript or Python. 


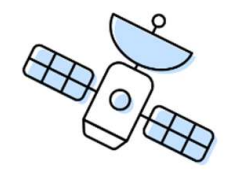

Satellite Imagery

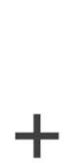

Your Algorithms

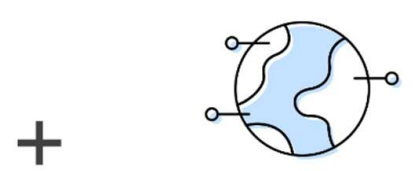

Real World Applications

Figure 2. Structure of the GEE [8].

In this study, a JavaScript program was written to differentiate water object from other land surface objects (e.g., vegetation, bare soil) and extract it from the Landsat image using Normalized Difference Water Index (NDWI). In GEE, NDWI is calculated through "normalized Difference" function from image bands B3 (green) and B5 (NIR) as below:

$$
N D W I=\frac{B 3-B 5}{B 3+B 5}
$$

The NDWI is to highlight the reflectance ability of water in the green wavelength compared to the near-infrared NIR wavelength. Pixels with NDWI greater than zero representing water pixels on image.

The water surface area in each Landsat image were calculated as the total number of the water pixels multiplied by the image resolution, which is formulated by "ee.Image.pixel Area" function in the GEE. The above procedure was repeated for all Landsat images that meet the cloud cover requirement to obtain the time-series of surface water area for each reservoir.

ArcGIS: This software is a geographic information system (GIS) for working with maps and geographic data maintained by the Environmental Systems Research Institute (Esri). The software can be used for creating map and analyzing mapped information. It has been widely used for applications in natural resources and environment. In this study, ArcGIS was used to create the surface water area-water level-water volume relationship from topographic map DEM. To do that a region corresponding with maximum water level of a reservoir was specified. Then, using geographic calculation tools in ArcGIS, the water surface area-water level-water volume for each reservoir was constructed.

\subsection{Landsat satellite data}

The Landsat satellite system was launched into orbit in 1972. Until now, eight generations of Landsat have been launched. Each satellite is equipped with a MSS (multispectral scanner), a set of RBP television radios. In this study, we used observation data from Landsat-8 Operational Land Imager (OLI) and Thermal Infrared Sensor (TIRS). Landsat-8 was launched in 2013 and provides data with spatial resolution of $30 \mathrm{~m}$ and temporal resolution of 16 days [9].

This study extracted and analyzed Landsat remote sensing images in order to study the variation of six hydropower reservoirs in the Chinese territory of the Mekong river including: Gongguoqiao Dam, Xiaowan Dam, Manwan Dam, Dachaoshan Dam, Nuozhadu Dam, Jinghong Dam and five other hydroelectric reservoirs on the Da River (in Red river system) including Yayangshan Dam, Shimenkan Dam, Longma Dam, Jufudu Dam, Gelantan (Figure 3). Study period is from January $1^{\text {st }}, 2015$ to February $29^{\text {th }}, 2020$. Landsat -8 images were collected from GEE's database. For removing the cloud impact, only images with a cloud cover lower than $10 \%$ were selected. 

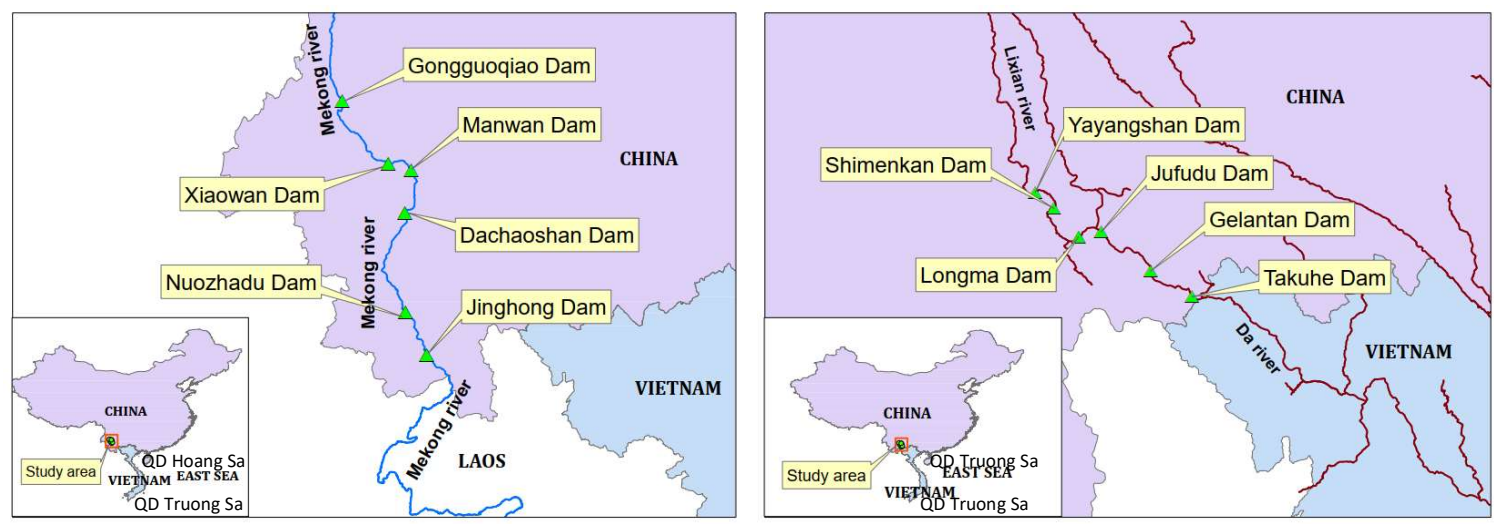

Figure 3. Locations of reservoirs on the Mekong (left) and Da River (right) in Chinese territory.

\section{Results}

\subsection{Variations of reservoir water level and volume on the Mekong River}

The variations of water level and volume of Xiaowan, Nouzhadou and Jinghong reservoirs during 2015-2020 period in the Chinese territory of the Mekong river basin from the upstream to downstream are shown in Figure 3-5. Xiaowan and Nouzhadou are the two largest reservoirs and Jinghong is the lowest reservoir in the cascade system of reservoirs in the Chinese territory. It can be seen that the Chinese reservoirs usually begin releasing water at the end of January and most of the reservoirs reach the lowest water level by the end of May. The sharp reduction of water level and volume of reservoirs from January to March indicates that the releasing flow is much larger than the inflow in this period.

From June to August, the reservoirs slowly store up water, which implied that the inflow to the reservoirs is slightly higher than outflow. From August to January, the reservoirs quickly fill up water. The reservoirs are full around the end of November to early January. It is worth noting that the water level of reservoirs in mid-February 2020 is lower than the water level at the same time of the other years, which indicates that the 2020 dry season is the driest in the 2015-2020 period. The similar trend was also found in the other reservoirs which are not shown here.

Water level of Xiaowan reservoir

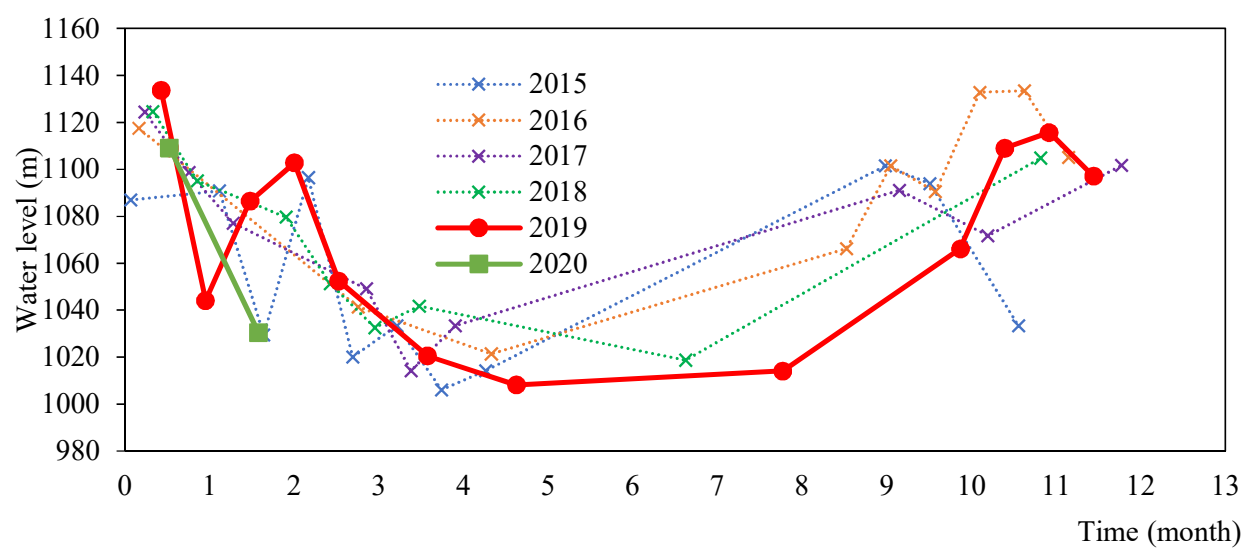




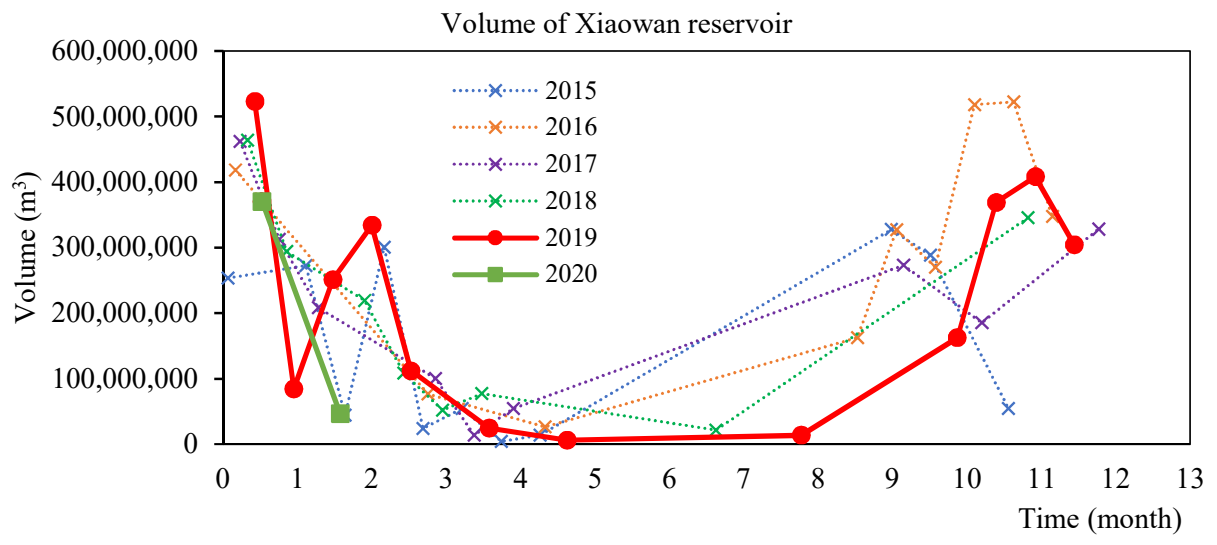

Figure 4. Changes in water volume and level of Xiaowan reservoir on Mekong river.
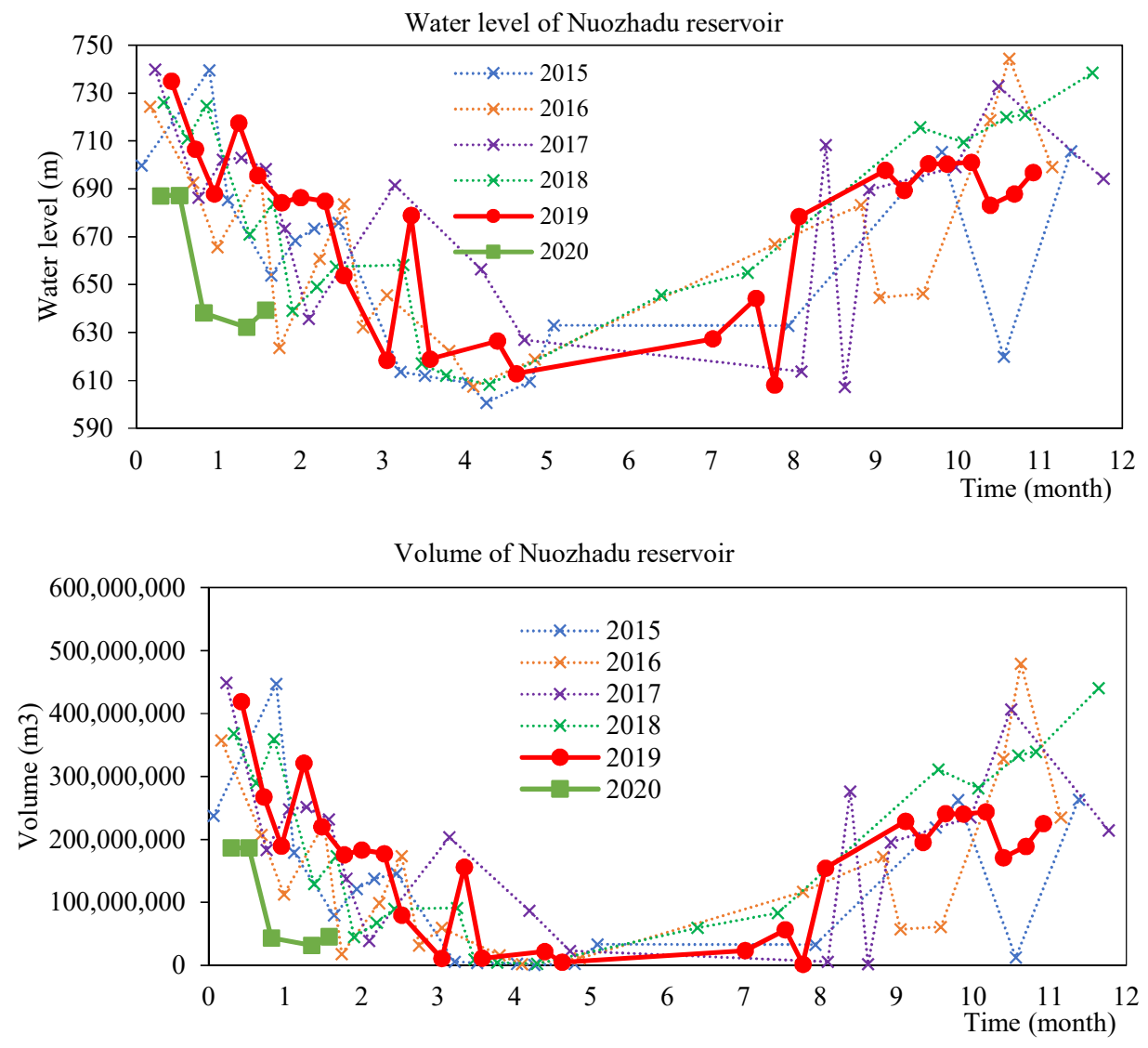

Figure 5. Changes in water volume and level of Nouzhadu reservoir on Mekong river. 

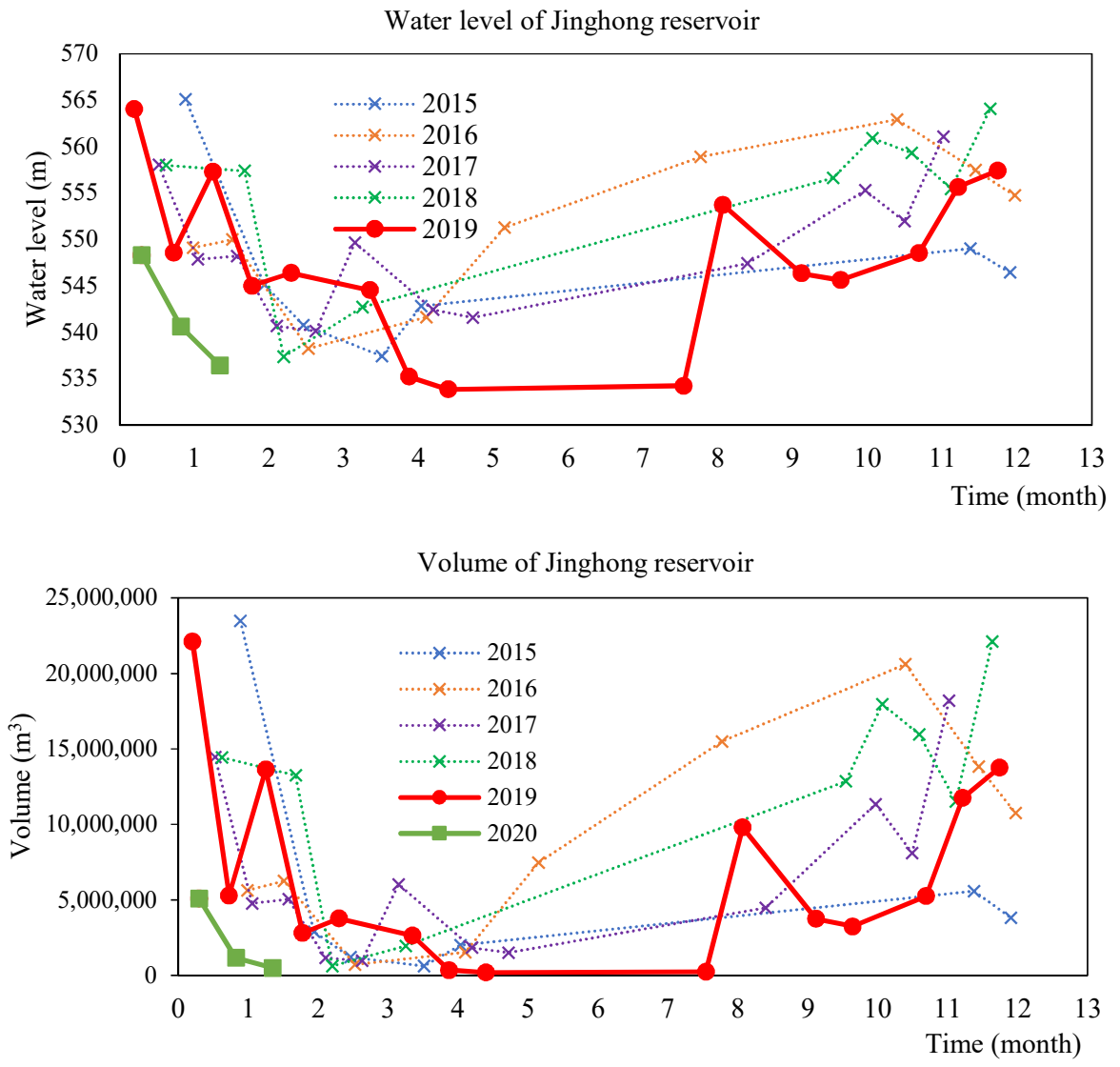

Figure 6. Changes in water volume and level of Jinghong reservoir on Mekong river.

\subsection{Variations of reservoir water level and volume on the Red River}

Due to the large reservoirs in the Red River basin outside the Vietnamese territory located on the Da river, the study concentrated on reservoirs in the Da river. Figures 6-8 present the variations of water level and volume of three reservoirs in the 2015-2020 period. From December, the outflow is larger than the inflow. By the end of March or early April, the reservoir volume reaches the lowest value of the year. From early May to mid-August, the reservoirs gradually fill up water. From mid-August to November, the reservoirs stores up water rapidly and the reservoirs usually reach the highest water level by November. This indicates that reservoirs in the Da river is one month earlier than those in the Mekong river.

It is worth noting that the water level of reservoirs in 2019 was quite different from the previous years due to the small amount of precipitation in the wet season. The reservoirs were not fully filled until the end of December. By the end of December, while reservoirs usually begin to release water in the other years, it is still on the progress of filling up in 2019. This leads to low amount of water released from these reservoirs to Vietnam in the dry season of 2019-2020. 

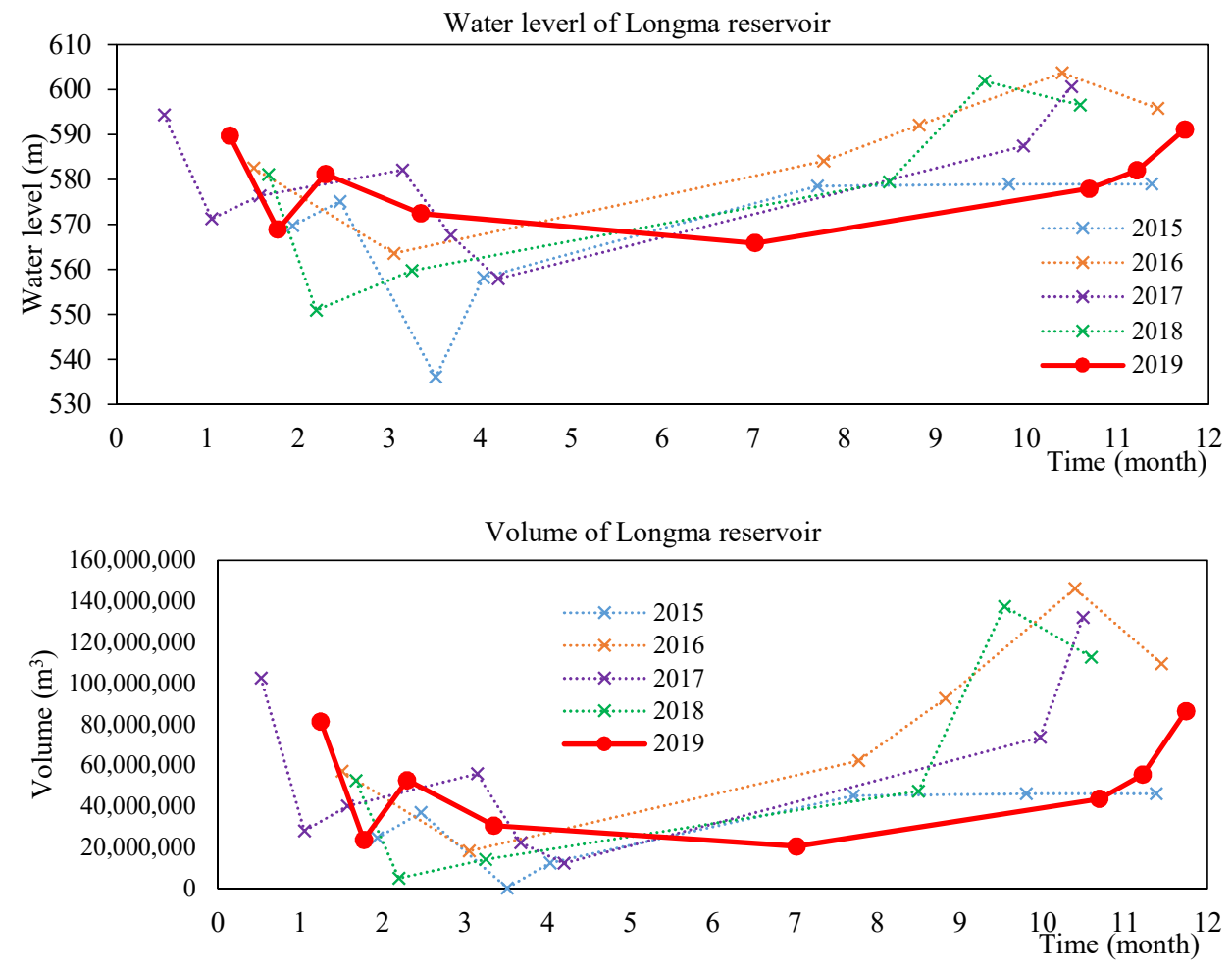

Figure 7. Changes in water level and volume of Longma reservoir on Da river.
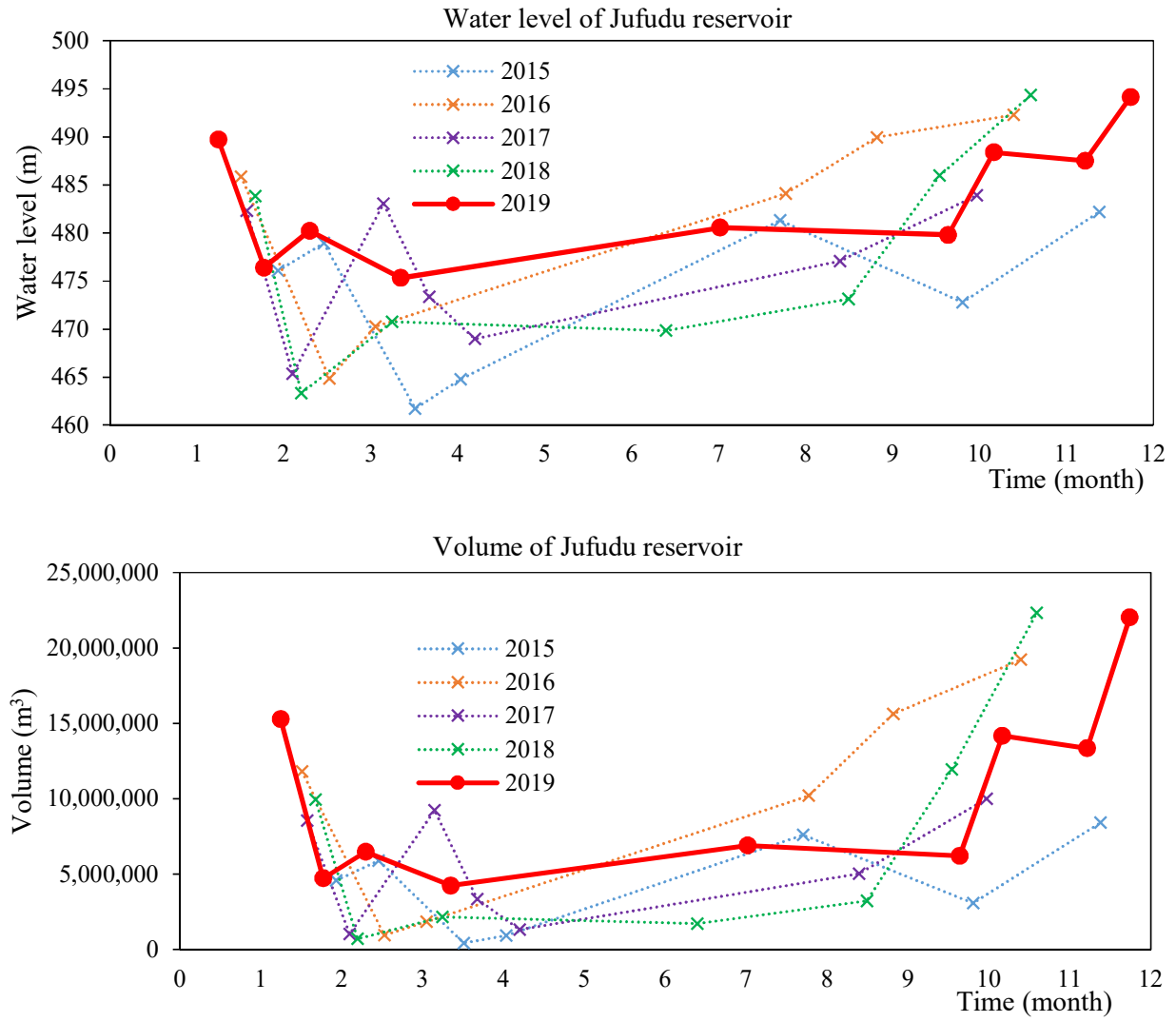

Figure 8. Changes in water level and volume of Jufudu reservoir on Da river. 

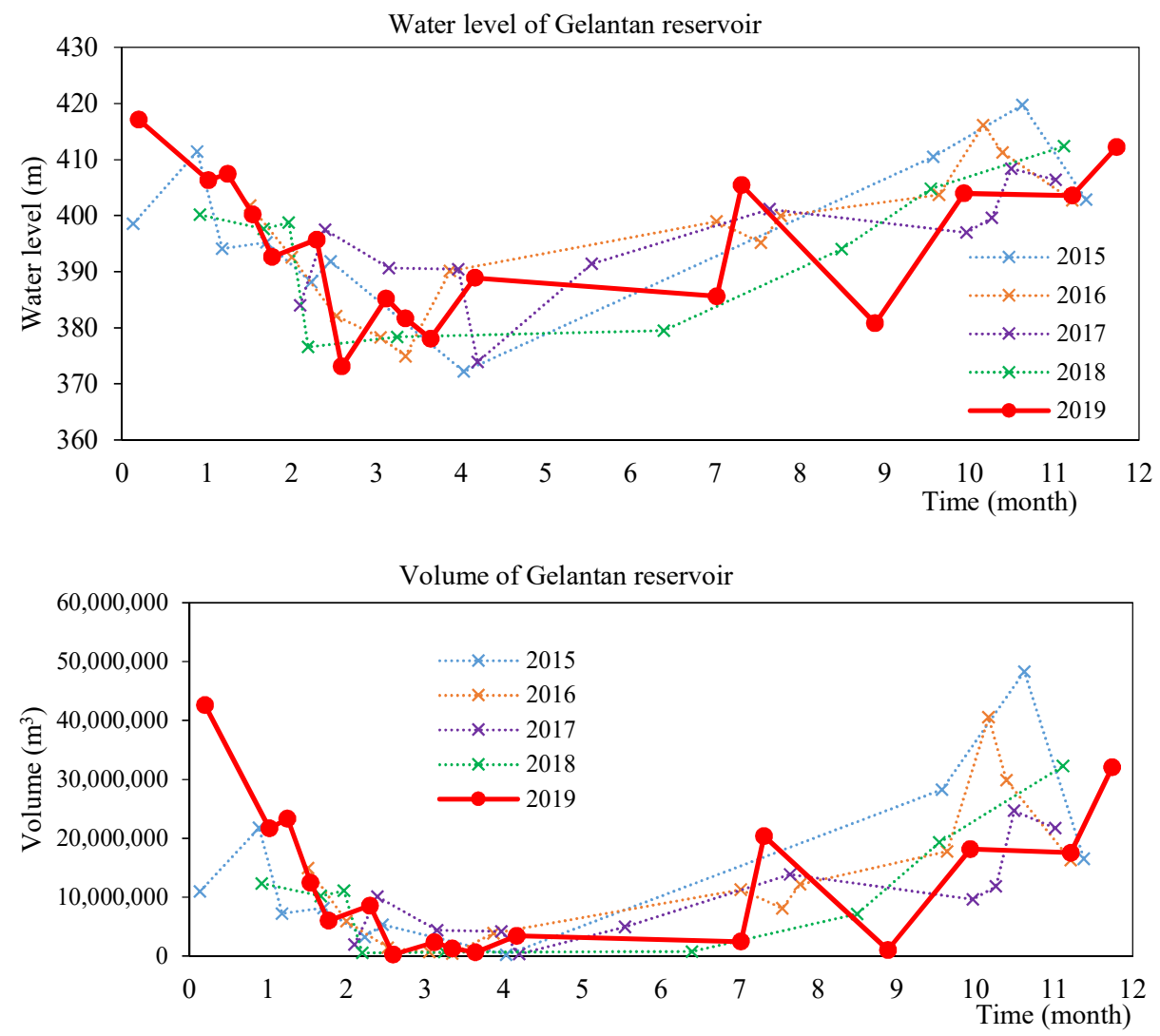

Figure 9. Changes in water level and volume of Gelantan reservoir on Da River.

\section{Conclusion}

One of the most challenging tasks for water resources forecasting and management in transboundary river basins is the shortage of observed data in foreign territories. This greatly reduces the accuracy of flow forecasting and limits the effectiveness of water resources management. While it is unfeasible to use conventional observation methods, remote sensing with its large coverage has a great potential to monitor water resources in foreign territories. However, so far there have been a few studies in Vietnam that evaluate the applicability of the remote sensing in water resources monitoring. This study focused on monitoring the temporal variations of water level and volume in the reservoirs in Mekong and Red river basins. While the GEE platform was used to quickly process a large amount of Landsat data to produce the time-series of water surface area, ArcGIS was employed to construct the water surface area-water level-water volume for each reservoir, which then was used to derive the time-series of water level and volume from the water surface area data. By combing the GEE platform and ArcGIS, we can observe the variations of water level and volume of reservoirs as well as analyze the reservoir operation schedules.

The water level and volume of reservoirs in the Mekong and Red rivers derived from the Landsat-8 data collected during the 2015-2020 period were analyzed. The results indicated that Landsat -8 can well monitor the temporal variations of reservoir water level and volume as well as reconstruct the operation schedules of reservoirs. The results also showed that the 
reservoir water volume in the 2020 dry season is lower than the other years in the 2015-2020 period due to lack of rainfall in both wet and dry season. These findings are valuable information that can be used for the water resources forecasting and management in the Red and Mekong rivers. However, due to low spatial and temporal resolution of the Landsat data, the changes in water surface area below $30 \mathrm{~m}$ and shorter than 16 days cannot be detected. In the next study, the remote sensing datasets with higher spatio-temporal resolution will be used to better monitor the variations of reservoir water level and volume.

Author Contributions: Conceptualization, D.H.S., N.A.D. and T.A.P.; methodology, T.M.C., T.A.P.; data analysis, T.M.C., T.A.P.; data curation, T.M.C., T.A.P.; writing-original draft preparation, T.A.P., T.M.C.; writing-review and editing, T.A.P., P.N.A., N.H.V.; visualization, T.M.C.; supervision, N.A.D., D.H.S. All authors have read and agreed to the published version of the manuscript.

Acknowledgments: We thank our colleagues from the Water Resources Institute who provided insight and expertise that greatly assisted the research. We also thank reviewers for their insight comments and suggestions that significantly improved the quality of this paper.

Conflict of interest: The authors declare no conflict of interest.

\section{References}

1. Vörösmarty, C.J.; Green, P.; Salisbury, J.; \& Lammers, R.B. Global water resources: vulnerability from climate change and population growth. Sci. 2000, 289, 284-288.

2. Munia, H.; Guillaume, J.H.A.; Mirumachi, N.; Porkka, M.; Wada, Y.; Kummu, M. Water stress in global transboundary river basins: significance of upstream water use on downstream stress. Environ. Res. Lett. 2016, 11, 1-12.

3. Kham, D.V. Research on remote sensing technology (RS) and geographic information system (GIS) in meteorology. Vietnam Institute of Meteorology, Hydrology and Climate Change, 2008.

4. Biancamaria, S.; Hossain, F.; Lettenmaier, D.P. Forecasting transboundary river water elevations from space. Geophys. Res. Lett. 2011, 38, 1-5.

5. Nishat, B.; Rahman, S.M. Water Resources Modeling of the Ganges-BrahmaputraMeghna River Basins Using Satellite Remote Sensing Data. JAWRA J. Am. Water Resour. Assoc. 2009, 45, 1313-1327.

6. Zhang, S.; Gao, H.; Naz, B.S. Monitoring reservoir storage in South Asia from multisatellite remote sensing. Water Resour. Res. 2014, 50, 8927-8943.

7. Le, H.H.; Tran, A.P.; Pham, N.A.; Cao, H.H.; Thai, Q.N. Application of remote sensing to monitor water level fluctuations in Kanak reservoir in Vietnam. Proceeding of VACCI, 2019, 132.

8. Gorelick, N.; Hancher, M.; Dixon, M.; Ilyushchenko, S.; Thau, D.; Moore, R. Google Earth Engine: Planetary-scale geospatial analysis for everyone. Remote Sens. Environ. 2017, 202, 18-27. 
9. Roy, D.P.; Wulder, M.A.; Loveland, T.R.; Woodcock, C.E.; Allen, R.G.; Anderson, M.C.; Helder, D.; Irons, J.R.; Johnson, D.M.; Kennedy, R.; Scambos, T.A. Landsat8: Science and product vision for terrestrial global change research. Remote Sens. Environ. 2014, 145, 154-172. 